\title{
Oficina Terapêutica de Mosaico de Papel: o lugar da materialidade no campo da Terapia Ocupacional
}
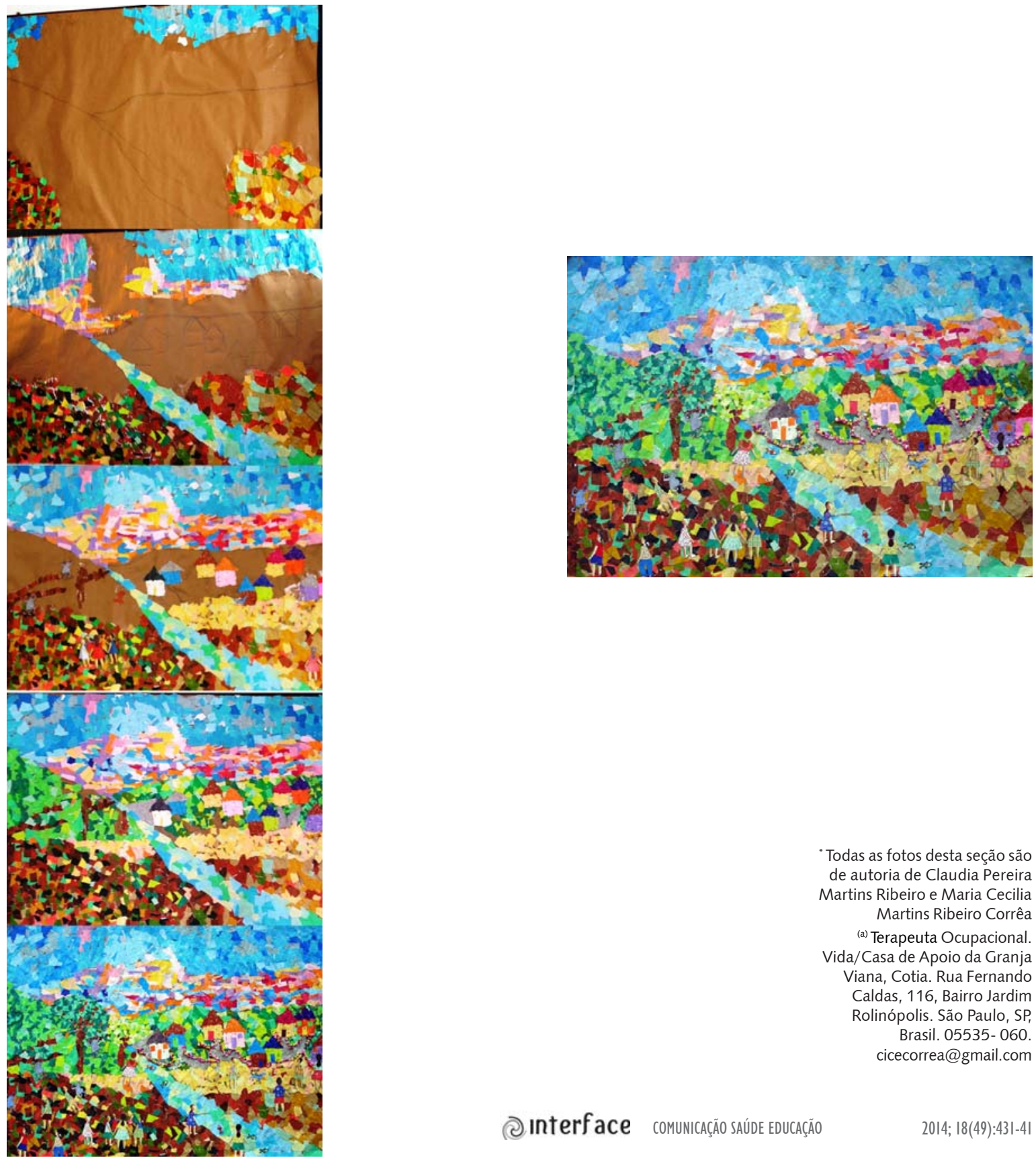

Todas as fotos desta seção são de autoria de Claudia Pereira Martins Ribeiro e Maria Cecilia Martins Ribeiro Corrêa

(a) Terapeuta Ocupacional. Vida/Casa de Apoio da Granja

Viana, Cotia. Rua Fernando

Caldas, 116, Bairro Jardim Rolinópolis. São Paulo, SP, Brasil. 05535- 060. cicecorrea@gmail.com 

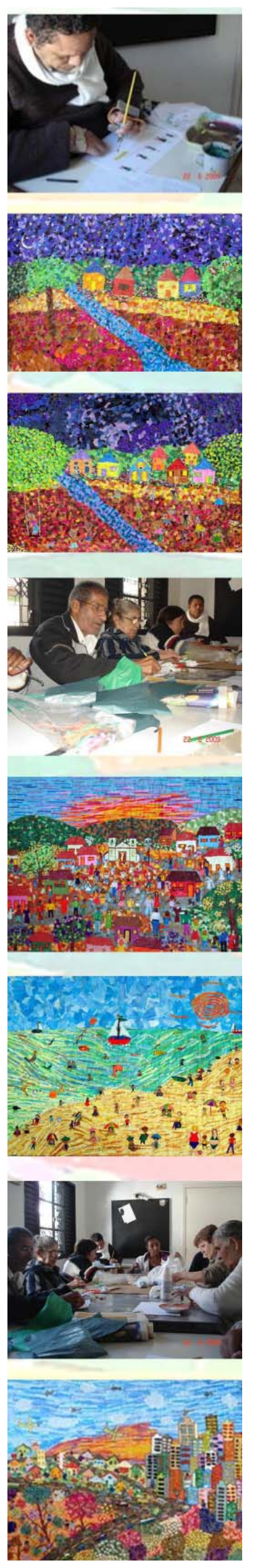

432 Dinterface
Eu perguntei um dia ao neurologista Oliver Sacks o que, do seu ponto de vista, era um homem normal. Ele me respondeu que um homem normal talvez seja aquele que é capaz de contar sua própria história. Ele sabe de onde vem (tem uma origem, um passado, uma memória em ordem), sabe onde está (sua identidade) e acredita saber aonde vai (ele tem projetos e a morte no final). Está, portanto, situado no movimento de um relato, ele é uma história e pode dizê-la para si mesmo ${ }^{1}$.

Envolvida na ideia de contar uma experiência clínica como terapeuta ocupacional, me surpreendeu a visita da palavra ponto... Ponto de partida, ponto de encontro, ponto de apoio, ponto cruz, ponto cardeal, ponto de parada, ponto de vista, ponto final... Ponto, segundo o dicionárioº é "a menor marca; lugar determinado" (p. 699).

Lugar determinado...ou será o "começo do caminhar prá beira de outro lugar"3. 


\section{Ponto de partida}

Lugar, do ponto de vista de Winnicott (p.31), é uma "posição básica a partir da qual a pessoa opera", é condição para o vir a ser, para o desenvolvimento de um sentimento de ser existente, é ponto de partida. Para falar sobre um trabalho clínico, considero importante clarear a partir de que lugar se opera, isto é, quais são os princípios que o norteiam.

Independentemente do contexto - saúde coletiva, consultório particular ou trabalho institucional - minha experiência clínica como terapeuta ocupacional orienta-se no pensamento psicanalítico, mais especificamente no MiddleGroup da psicanálise inglesa, sobretudo no autor Donald D. Winnicott.

Partilho de sua concepção sobre o ser humano. Para ele, o ser humano é um ser criativo, em constante amadurecimento e dependente, para efetivação dessa tendência inata, da comunidade em que vive. A respeito do ser criativo, Winnicott nos fala da capacidade e necessidade humanas de criar o mundo, criar sentidos próprios para seu viver a partir da sua apreensão singular do mundo compartilhado, mundo que inclui o real material e os processos inconscientes, afetivos, corporais, imaginários envolvidos nessa experiência. Dessa forma, ser criativo não se refere ao fazer artístico, mas sim ao aparecimento do singular de si mesmo, experiência que envolve coragem e implica os riscos do viver.

Ao considerar a criatividade uma das condições fundantes do ser humano, posso dizer que o potencial criativo é fonte de saúde. Assim, saúde passa a se relacionar com modos de ser, com bem estar próprio e completo, implicando uma continuidade e as conexões entre os aspectos biológicos, culturais, sociais, psicológicos e ambientais; deixa de ser "coisa" da doença e passa a ser garantia de vida, de qualidade de vida. Essa visão, que se contrapõe ao ideal de saúde, isto é, à compreensão que define saúde como "ausência de doença" e que concebe o corpo como uma máquina que deve ser consertada, caso dê algum defeito, apresenta a noção que nosso corpo não é uma máquina, um mecanismo, mas um complexo vivo e singular. Assim, podemos estar enfermos - etimologicamente 'não firmes' - e ainda assim estarmos capazes, criativos e saudáveis em diversos outros aspectos de nossa vida ou atividade ${ }^{5}$.

Coerente com os pressupostos acima, minha prática clínica norteia-se pelo respeito à singularidade do paciente, pela consideração de suas necessidades. Trata-se de uma relação de cuidado genuína, um encontro interhumano em que o terapeuta relaciona-se de igual para igual com seu paciente, vendo-o como potente, integral, que busca as suas soluções para sua vida, pois ele sabe mais sobre si do que qualquer um. Isso implica na assunção de um compromisso ético diante da pessoa em sofrimento, no estabelecimento e na manutenção de uma situação terapêutica que favoreça a continuidade de ser, a esperança de o paciente se sentir vivo e real; isto é, ir sendo-se no seguimento do tempo e no espaço compartilhado com o outro na sua comunidade.

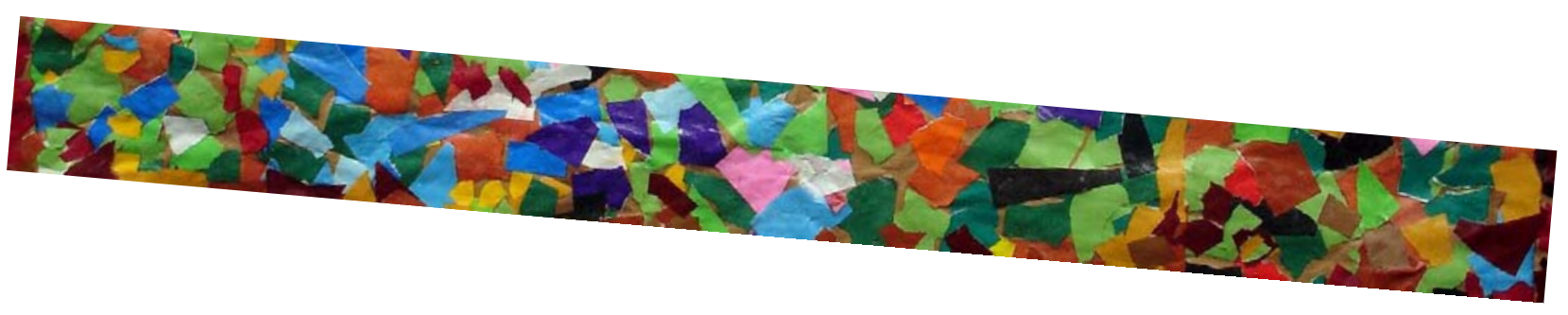




\section{Ponto de referência}

A experiência que relato aqui, ainda em curso, teve início em agosto de 2005, quando fui chamada por uma instituição sem fins lucrativos do terceiro setor para realizar atividades com um grupo de pessoas com deficiência física, adultos que viviam em situação de exclusão e vulnerabilidade social.

Na primeira entrevista com os responsáveis da instituição, observei que o pedido era de entretenimento para os pacientes e respondia a uma necessidade institucional de vê-los ocupados durante todo o dia. Tratava-se, portanto, de uma visão que desconsidera necessidades humanas fundamentais, sendo conivente com práticas clínicas objetivantes, o que não é aceitável, nem do ponto de vista da clínica, nem eticamente. Contudo, encontrei espaço institucional para iniciar os encontros de acordo com meus princípios, buscando resgatar nos pacientes a condição de seres humanos criadores.

Desde então, essa intervenção, que denomino Oficina Terapêutica de Mosaico de Papel, acontece em grupo, sendo este aberto $^{(b)}$ e formado no máximo por dez pacientes de ambos os sexos e na faixa etária compreendida entre quarenta e setenta anos. Até 2012, todos os participantes apresentavam deficiências físicas, em sua maioria adquirida e decorrente de diferentes etiologias, como: acidente vascular encefálico, aneurismas ou lesão medular devido a traumas. Atualmente, o enquadre permanece o mesmo, porém o grupo é composto exclusivamente por participantes idosos, com ou sem deficiências físicas.

A oficina terapêutica que apresento neste relato, a primeira de uma série que venho realizando na mesma instituição, ocorria uma vez por semana, com uma hora e meia de duração. A atividade que propus foi o mosaico de papel. $O$ principal critério para escolha da atividade foi minha afinidade, experiência e confiança no potencial transformador do material. Penso que, independentemente dos contextos ou objetivos terapêuticos, a escolha inicial por um material e/ou atividade não está só relacionada a uma técnica, pois não existem pacientes iguais ou terapeutas iguais. Envolve, sempre, a apresentação de modos de ser do terapeuta - sua pessoa, sua história, sua vivência com o material e/ou atividade, as teorias que o acompanham, sua atitude de cuidar e a capacidade de considerar as necessidades fundamentais dos pacientes.

Os papéis coloridos foram apresentados aos participantes do grupo, junto com um convite para que, a partir de suas histórias de vida, criassem uma figura sobre o suporte - uma folha de papel Kraft de 1,20m X0,90m com uma linha traçada em seu sentido longitudinal, que denomino linha do horizonte.

A imagem com mosaico de papel foi criada e confeccionada coletivamente, com todos os pacientes acomodados ao redor de uma mesa, tendo o papel Kraft ao centro. Cada um contribuiu para construção do painel de mosaico de acordo com sua possibilidade e disponibilidade. Assim, existem alguns pacientes que podem cortar e colar papéis, outros podem pintar ou cortar e há também aqueles que podem narrar o que está sendo construído pelo grupo.

O objetivo inicial do atendimento foi propiciar um ambiente favorável à comunicação, ao relacionamento entre as pessoas do grupo e entre estes e a terapeuta, ao acolhimento das diversas formas de expressão, ao alívio do sofrimento e ao desenvolvimento da capacidade de brincar.

Posso dizer que a Oficina Terapêutica de Mosaico de Papel, além de cumprir com os objetivos, surpreendeu-me ao revelar uma qualidade de potencial terapêutico que justifica ser seriamente pensado e recriado em diferentes contextos, pois responde a algumas necessidades que vêm sendo delineadas e encontradas na clínica contemporânea da terapia ocupacional.

\author{
(b) O grupo aberto não \\ tem prazo para término e \\ permite que dele entrem \\ e saiam pessoas a \\ qualquer momento do \\ desenvolvimento da \\ proposta.
}




\section{Ponto de encontro}

Walter Benjamin ${ }^{6}$, refletindo sobre a narrativa, diz que é uma forma artesanal de comunicação sendo sua matéria prima a experiência. Sendo o vivido sua matéria prima, a narrativa coloca todos nós na posição de donos de um saber originado na própria experiência. A natureza viva das narrativas permite, a cada leitura, a atualização da experiência, pois possibilita a reflexão, o desvelamento de novos sentidos e a construção continuada do conhecimento sobre o vivido narrado.

Sendo assim, lanço mão das narrativas para registrar os encontros clínicos. Ao escrever, reflito sobre meu trabalho, o paciente e/ou grupo e as experiências alcançadas. Elas são elaboradas em momento posterior às sessões, com base nas lembranças dos encontros terapêuticos. Nesta experiência, a narrativa foi realizada após a finalização da construção do painel.

Trago aqui, então, o relato da construção do primeiro quadro da Oficina Terapêutica de Mosaico de Papel:

Fui chamada para entreter um grupo de pessoas adultas, descrito assim: deficientes físicos, desvitalizados, que passavam o dia "desocupados e entediados". Atendo o chamado. Vou para a instituição acompanhada da fé no ser humano, de meus princípios, de alguns conceitos e preconceitos e, também, de papéis coloridos e cola.

$\mathrm{Na}$ minha imaginação, as limitações físicas seriam grandes obstáculos, fato que logo se transformou, pois encontrei pessoas vivas que queriam conversar, contar suas histórias - seu passado, seu presente e, quem sabe, desenhar seu futuro. Queriam atenção, necessitavam de tempo e disponibilidade afetiva. Nesse primeiro encontro, dentro de mim, proponho-me a viver com esse grupo uma experiência no tempo que ele demandasse.

Iniciamos nosso primeiro encontro conversando sobre nossas origens: nosso nome, onde nascemos, como éramos chamados, como vivíamos, do que brincávamos, o que cantávamos, "causos" que ouvíamos e tudo mais que viesse à tona. Em meio a um turbilhão de falas e memórias, abriu-se no grupo a possibilidade de apresentação e compartilhamento dos seus diferentes universos e também dos seus pontos em comum, sendo a vivência da roça, do campo, partilhada pela maioria. A partir desse lugar, dessa marca em comum, definimos o tema da paisagem a ser coletivamente construída, usando o mosaico de papel: um campo.

O grupo estava desconfiado, porém entusiasmado, e após esclarecimento sobre o que é um mosaico de papel e como seriam nossos encontros, iniciamos o trabalho: picar papéis e colá-los no suporte, um papel Kraft grande, que ocupava praticamente toda a mesa, com uma linha desenhada a qual chamo de linha do horizonte. Durante a construção do céu e do chão, o fundo da nossa paisagem, um grupo esperançoso, embora muito hesitante, emerge e, surpreendido pela experiência brincante, arrisca-se e faz, possibilitando-me vislumbrar seu potencial criador através da dimensão lúdica alcançada.

O céu e o chão da nossa paisagem vão aparecendo, e junto com eles a confiança na terapeuta e as dificuldades de realização. Impôs-se, em nossos encontros, a doença, o limite, o corpo impedido e estranho, a vida tragicamente interrompida. Porém, a plasticidade característica do mosaico de papel permite adequar os fazeres com as disponibilidades, possibilidades e limites do grupo, favorecendo as relações, criando um clima de cumplicidade e coesão entre os participantes e garantindo a continuidade da oficina.

Concluímos o fundo e junto surgiu a questão: quais figuras vão compor esse fundo? O que habitará essa paisagem? O momento é de pôr vida no lugar, de colar as figuras no fundo.Assim, cada pessoa escolhe um animal para colocar no quadro.

Depois dessas escolhas, me dei conta da aproximação existente entre o animal e o paciente que o elegeu. Sendo assim, vou usar os animais escolhidos para representar e apresentar cada paciente do grupo: 
O Cavalo - o paciente viajante. Não pode rasgar, colar e nem se locomover. Imagina e fala com e pelo grupo, há diferenças no seu nível sociocultural, escreve no computador e, além de enriquecer o grupo com suas colocações, "topa" escrever uma narrativa dos nossos encontros, vamos ver...

O Pavão - a paciente vaidosa. Fala sem parar, diz que sua mão ficou "boba"(c). Aceita minha ajuda para colar os papéis e acolhe, durante o grupo, minhas interferências em seu monólogo, abre sua fala para um diálogo: olha para o grupo, escuta.

O Passarinho - a paciente delicada. Fala muito pouco, não tem autonomia para se locomover. Mostra lindos olhos azuis e um sorriso tímido que me encantam. Tem uma fala mansa, baixinha, difícil de entender, mas, tímida, rasga e cola o papel no suporte com autonomia - marca sua presença naquele espaço à sua maneira: silenciosa, delicada e livre.

A Arara - a paciente barulhenta. Lembra-se e fala de sua história, conta "causos" e canta: "Saudades, palavra triste...". Fala de seu passado: boa filha dedicada, agora solteira e solitária. Revela-se brincalhona, participativa, acolhe as ideias do grupo, rasga e cola os papéis com autonomia. Surpreende-se e encanta-se com a paisagem colorida que vai sendo construída. Ranzinza, afasta-se temporariamente do grupo.

A Onça Pintada - o paciente hábil. De nome difícil de lembrar, também tem mão boba. Alegre, pedreiro com muito orgulho, habilidoso e caprichoso "assentador" de papéis. Vejo-o assentando tijolos enquanto cola papéis.

O Elefante - a paciente densa. Curiosa, desconfiada,

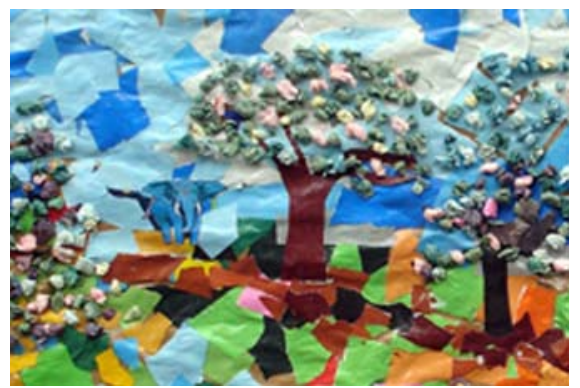
subjetivamente pesada, tem autonomia, mas sem andar. Por necessidade e empatia - creio eu - topou de imediato a experiência, ajuda-me muito com sua atitude colaborativa, com suas conversas. Mineira, olha-me pelo canto dos olhos, a sensação que tenho é de que ela vê tudo; companheira.

A Arara também - a paciente viva. Não pode tocar em nada, tudo dói. Conta para o grupo sua história de amor e movimento - esposa de um caminhoneiro, vivia com ele pelas estradas da vida. Surpreendente, denuncia: "um dia acordei assim, com um corpo que não é o meu!" Presença viva e espontânea no grupo - sofre.

E eu, passarinho também. Passarinha sutil, zelosa e atenta às necessidades do grupo. Alimenta-o em doses diminutas, acredita no potencial do grupo para alçar voos.

Apresentado o grupo, continuo nossa história.

Iniciamos pelas árvores. Olhamos nosso trabalho de perto, contemplamos de longe, conversamos sobre nossas árvores preferidas, observamos atentamente um quadro do Monet da parede da nossa sala, falamos sobre a paisagem do campo que estamos construindo e escolhemos o lugar das árvores: as grandes nas pontas e as pequenas no centro.

Meu sentimento era de tensão, atravessávamos um momento de risco? A arara, a paciente barulhenta, não quer mais participar. Serão ressonâncias da lucidez a respeito da precariedade da vida? Será o momento - colar figuras no fundo? Será um mal estar geral da convivência em grupo? Não sei.

Sentia-me inteiramente comprometida com nossa experiência; juntos, experimentávamos a visita da ansiedade e da angústia. As árvores que fizemos e colamos nesse dia não sobreviveram - não satisfizeram o grupo e foram retiradas do mosaico no encontro seguinte. (c) "Mão boba" - termo de senso comum usado no grupo para se referir à sequela física adquirida em um dos membros superiores. 
Questiono (comigo mesma) se colar as árvores naquele momento não estava a serviço de remendar o que vivíamos: nossa imersão nas dúvidas quanto à qualidade de nossos vínculos e, consequentemente, quanto à confiança na continuidade da experiência. Sendo assim, como colar a figura? Como aparecer no grupo? Como prosseguir?

A partir daqui, o universo de vivências desse grupo passa a ser compartilhado durante as colagens: as dificuldades com escaras, e o paciente que necessitou amputar suas pernas porque não cuidou delas. As infecções urinárias, e a paciente que foi hospitalizada. A dificuldade de enxergar e de ir ao oculista. A raiva e a dor de, um dia, repentinamente, acordar com um corpo que não reconhece como seu e que não responde à sua vontade - acordar sem entrever a liberdade.

A minha abertura e disponibilidade verdadeiras para estar com o grupo, somadas à continuidade dos nossos encontros, possibilitaram a explicitação, cada vez mais profunda e intensa, das suas questões: a vida interrompida, a discriminação e exclusão social, a submissão e invasão pelo outro, a falta de sentido para a fatalidade, o potencial precocemente morto, a solidão. Dessa vez, compartilhando as sofridas experiências humanas, encontramos solução para tronco, folhas e flores da nossa paisagem, que agradou a todos. As árvores sobreviveram e nós também!

Nesse momento, aparece no grupo a valorização do nosso processo, a surpresa com a paisagem que vem sendo construída e o pedido de fazer a colagem nos dias em que não estou na instituição. Acolho o pedido, deixo os materiais com a enfermagem.

Estamos chegando ao fim: as árvores na paisagem estão praticamente prontas, resta colar os animais escolhidos. A arara, a paciente barulhenta, visita o grupo, admira-se e surpreende-se com a paisagem, retoma entusiasmada a atividade. O grupo, paradoxalmente, parece não finalizar, surgem novas ideias. Pergunto-me: estamos adiando o fim? Será um novo projeto? Estamos nos aprontando para irmos embora?

Colamos os animais, cada paciente escolhe um lugar para o seu. Reflito e falo para o grupo sobre a importância de enriquecermos nossa paisagem com animais, seres de movimento que inspiram liberdade, e como foi rico imaginar o que tinham para contar do lugar a partir do qual podiam olhar e interagir com a paisagem criada.

Solitária, olho para o quadro e lembro-me do artista Milton Dacosta, da sua obra intitulada "Roda"7 . Um paciente brinca, com seu olhar e imaginação, de encontrar pessoinhas e outras figuras nos pedacinhos de papel que compõem nossa paisagem e acaba por lamentar a ausência de pessoas, expressando o desejo de incluí-las no mosaico.

Com essa fala, sinto-me autorizada a apresentar para o grupo a "Roda". Na sessão seguinte, trago a imagem. Todos gostam, brincam, lembram-se de suas cirandas. A figura é recortada e colada, acrescentamos mais dois meninos e, assim, todos do grupo estão lá humanizados - a vida, a brincadeira instala-se em nosso encontro.

Último dia, celebramos o fim. Entrego para cada paciente um cartão postal com a imagem do nosso mosaico, o título da nossa obra é colocado - "Um lugar, O Campo".

Chegamos ao fim: "Fazer um fim é fazer um começo", como disse Elliot ${ }^{8}$ (p.153), o poeta. As ideias que me animam agora são aberturas para novos projetos com esse grupo.

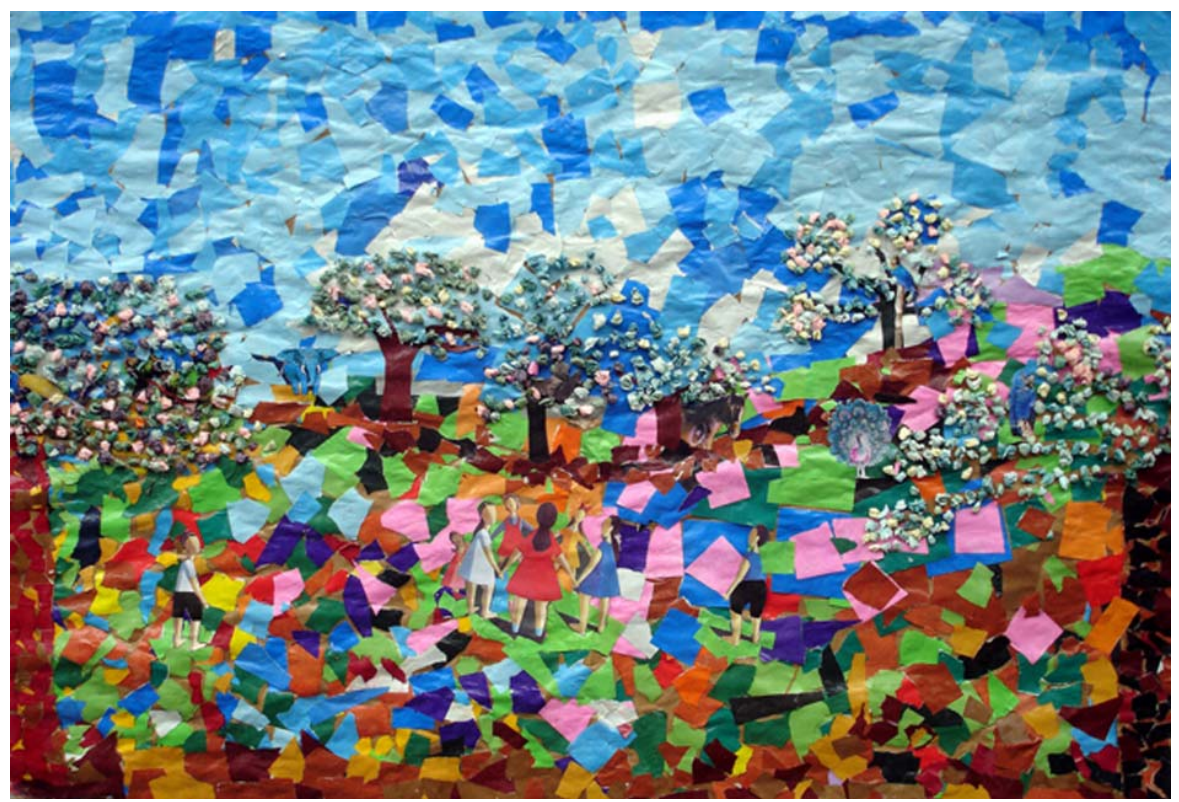


CRIAÇÃO

\title{
Ponto final?
}

\author{
"o barro \\ toma a forma \\ que você quiser \\ você nem sabe \\ estar fazendo apenas \\ o que o barro quer"8 (p. 107)
}

De fato, essa experiência abriu novos mundos para a minha experiência - a respeito da clínica, dos sofrimentos e condições existenciais experimentadas pelas pessoas com deficiência - e para o grupo no alcance de novos fazeres, de novas posições diante do outro, de algum acesso e convívio com a comunidade.

Na clínica, uma das situações que se abriu para minha reflexão e aprofundamento foi a apresentação e uso dos materiais. Como contei antes, me apresentei ao grupo com os papéis coloridos e cola, material e terapeuta juntos, à disposição dos pacientes, para acolher e testemunhar seus gestos criativos, seus processos singulares de criação, de retomada do potencial criativo, do processo de ativação da saúde.

Safra ${ }^{9}$ fala sobre a relação profunda entre o ser humano e a materialidade, destacando que os materiais esperam a ação humana, com sua criatividade, para ganhar significado. Nessa condição, estão abertos para receber o gesto e tornarem-se narradores do trabalho para as gerações futuras. Quando o material é reduzido à sua funcionalidade ou à sua estética, ele se torna impessoal, perde seu estatuto,

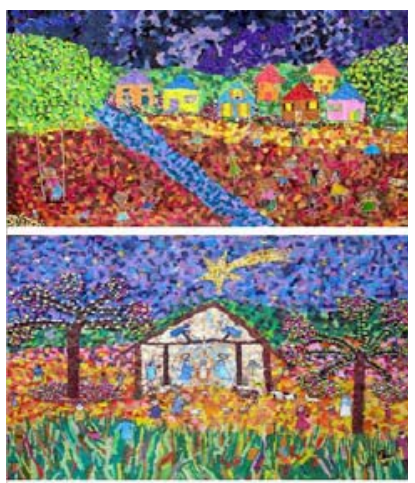
não veicula mensagens, objetifica-se, adoece o ser humano. Sendo assim, na situação clínica, o material que traz a marca do convívio com o terapeuta carrega sentidos e significações, auxilia no cuidado do sofrimento humano.

Considerando que o material carrega marcas do terapeuta, destaco a necessidade de refletirmos sobre a importância da constância do material e da atividade, oferecidos pelo terapeuta ao paciente, dentro do enquadre clínico de um processo terapêutico, o que nem sempre observamos nas salas de atendimento da terapia ocupacional. A experiência que abordo aqui usa o mosaico de papel desde seu início, em 2005, sendo que a diversificação e ampliação do uso dos materiais aconteceram, ao longo do tempo, sempre a partir do reconhecimento de uma demanda dos pacientes assentada no desejo de melhorar a expressão plástica da atividade em realização.

Conhecido de todos nós, o mosaico de papel ganhou sentido singular para esse

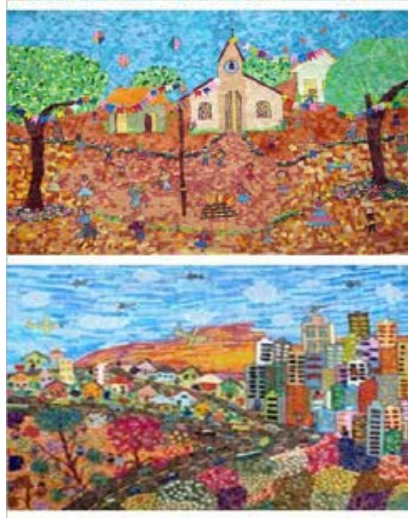
grupo. Passou a ser metáfora de sua experiência - tanto os papéis são rasgados e encontram, através do grupo, novas formas quanto essas pessoas foram interrompidas na continuidade de suas vidas e criam/encontram, no uso dos papéis, novas maneiras de ser, de fazer e de estar no mundo. O grupo se deu um nome Coletivo Mosaico de Nós.

Penso que o enquadre terapêutico é composto por aspectos objetivos, tais como o material, a atividade, as características do grupo e, nesse caso, da instituição, como também de aspectos subjetivos representados pela presença autêntica do terapeuta. A constância do enquadre, somada a sustentação, ao longo do tempo, da experiência de encontro inter-humano e de criação é que permite o estabelecimento de um vínculo de confiança, o vislumbre da esperança e da condição da capacidade de brincar. É nessa experiência de confiança e estabilidade

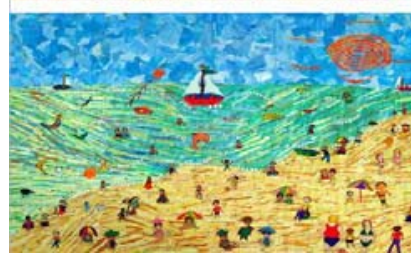
que surge um coletivo, que, na sua ação sobre a materialidade, articula as histórias vividas a momentos criativos, descobre modos próprios e diversos de fazer e de comunicar, brincar e imaginar ${ }^{10}$. Arrisca-se e põe em marcha seu desenvolvimento, sua continuidade de ser. 
Winnicott ${ }^{11}$ diz que brincar é fazer alguma coisa em algum lugar e que isto leva tempo. Estamos nessa brincadeira há nove anos. Na sala de atendimento, tudo é possível e transformável. Mundos são imaginados, criados e construídos, sempre atravessados pela vida além da sala - lembranças, amores, dores, histórias, encontros e desencontros; tudo anima nossas sessões.

Fora da sala de atendimento, o mundo compartilhado. Os encontros terapêuticos possibilitaram a construção de um acervo de catorze painéis de mosaico de papel e o blog ${ }^{12}$ : mosaicosdenos.blogspot.com.br. Este acervo imprimiu transformações nas vidas dos participantes, pois abriu condição tanto para geração de renda (através de venda de postais e calendário) como para a participação na vida cultural, a partir das exposições dos painéis construídos em espaços públicos da cidade. Expor seus painéis deu ao grupo visibilidade social, acesso à vida cultural, restaurou a dignidade dos pacientes a partir do fato de poderem mostrar à comunidade produtos de sua capacidade criadora. O Blog permitiu uma conversa entre o coletivo e a comunidade. Instala-se um lugar uma posição a partir da qual se opera.

Para finalizar, digo que essa experiência também inaugurou um lugar para esta terapeuta, o trânsito com seus pacientes pelo mundo de dentro e de fora, na interface da Arte e Produção da Saúde, levando seus princípios em qualquer contexto de trabalho.

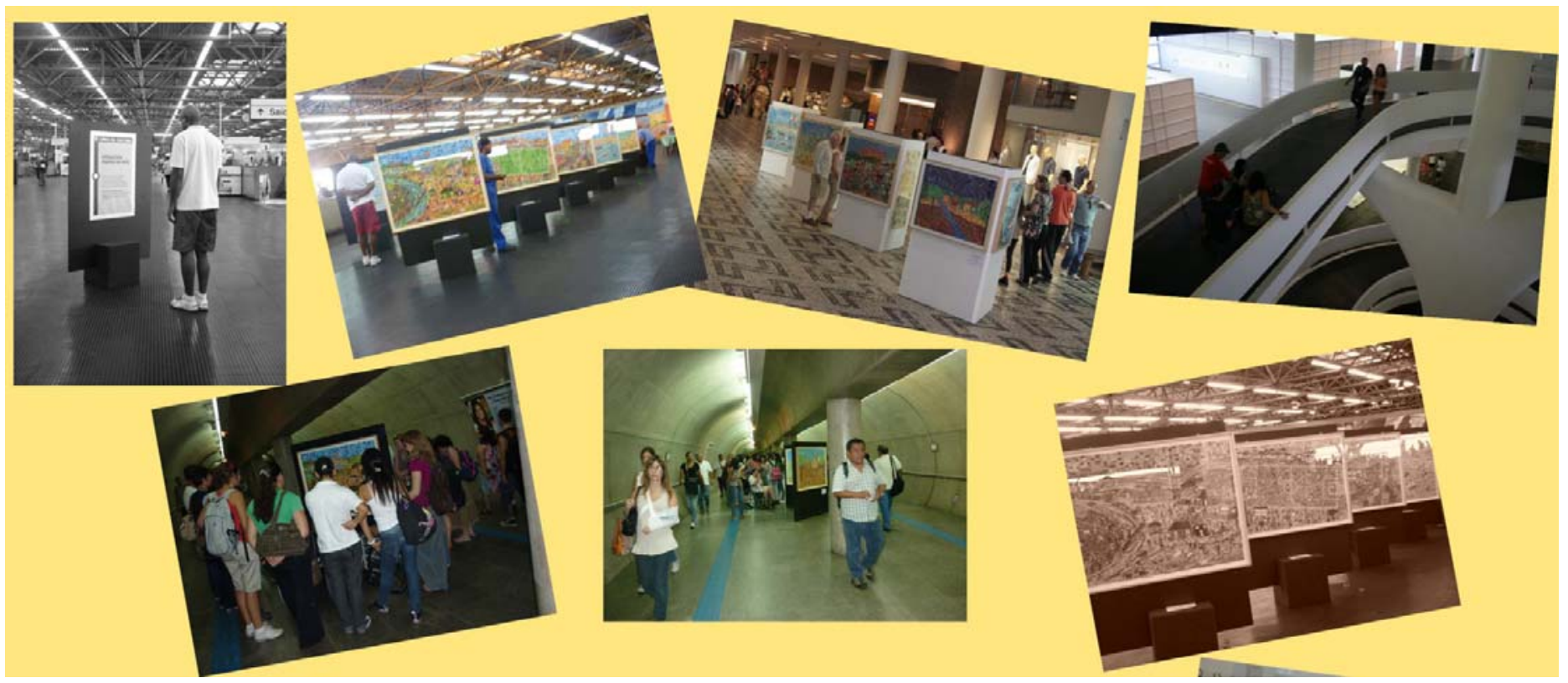


Este artigo versa sobre uma experiência clínica denominada Oficina Terapêutica de Mosaico de Papel, concebida para atendimento grupal de pessoas com deficiência física, em situação de exclusão e vulnerabilidade social. Esta intervenção, ainda em curso, ocorre no âmbito da Terapia Ocupacional, orientando-se no pensamento psicanalítico, sobretudo em Winnicott. O artigo discute os temas: escolha e uso dos materiais na terapia ocupacional, análise do potencial terapêutico e alcance deste enquadre clínico. Aproxima-se destas questões por meio da narrativa da construção coletiva do primeiro quadro da oficina. Os encontros abriram novas dimensões da experiência da clínica e das condições existenciais e dos sofrimentos experimentados pelos participantes. A efetividade terapêutica dessa intervenção, que transita na interface entre arte e produção de saúde, mostra-se pela possibilidade de novos fazeres, de novos papéis diante do outro, de participar mais de perto da vida comunitária.

Palavras-chave: Terapia Ocupacional. Oficina Terapêutica. Arte. Produção de Saúde.

\section{Paper Mosaic Therapeutic Workshop: the place of materiality in the field of Occupational Therapy}

This paper examines a clinical intervention model, Paper Mosaic Therapeutic Workshop, developed to assist people with physical disability and experiencing exclusion and social vulnerability. This ongoing intervention belongs to the field of occupational therapy and is based on psychoanalytical theory, specifically that of Donald Winnicott. The choice and use of materials in occupational therapy and analysis of the therapeutic potential and reach of this intervention are discussed. These topics are approached through a narrative of the collective construction of the first workshop paper mosaic. The group meetings opened new dimensions regarding clinical experience and existential conditions and suffering experienced by the participants. The therapeutic effectiveness of this intervention, operating in the interface between art and health production, was confirmed by the acquisition of new abilities and roles in relation to others, and closer participation in community life.

Keywords: Occupational Therapy. Therapeutic Workshop. Art. Production of health.

Taller Terapéutico de Mosaico de Papel: el lugar de la materialidad en el campo de la Terapia Ocupacional

Este artículo versa sobre una experiencia clínica: el Taller Terapéutico de Mosaico de Papel para la atención grupal de personas con discapacidad física en situación de exclusión y vulnerabilidad social. Esta práctica transcurre como Terapia Ocupacional y se orienta según el pensamiento psicoanalítico, basándose en Donald Winnicott. Se abordan estos temas: elección y uso de los materiales en terapia ocupacional, análisis del potencial terapéutico y alcance del encuadre clínico. Se efectúa una aproximación a través del relato de la construcción colectiva del primer cuadro en el taller. Los encuentros abrieron nuevos mundos en la clínica en relación con los sufrimientos de los participantes y sus condiciones existenciales. El alcance de nuevos quehaceres, nuevas posturas frente al otro, un cierto acceso y la convivencia con la comunidad muestra la eficacia terapéutica de esta propuesta situada en la interfaz arte-producción de salud.

Palabras clave: Terapia Ocupacional. Taller terapêutico. Arte. Producción de salud. 


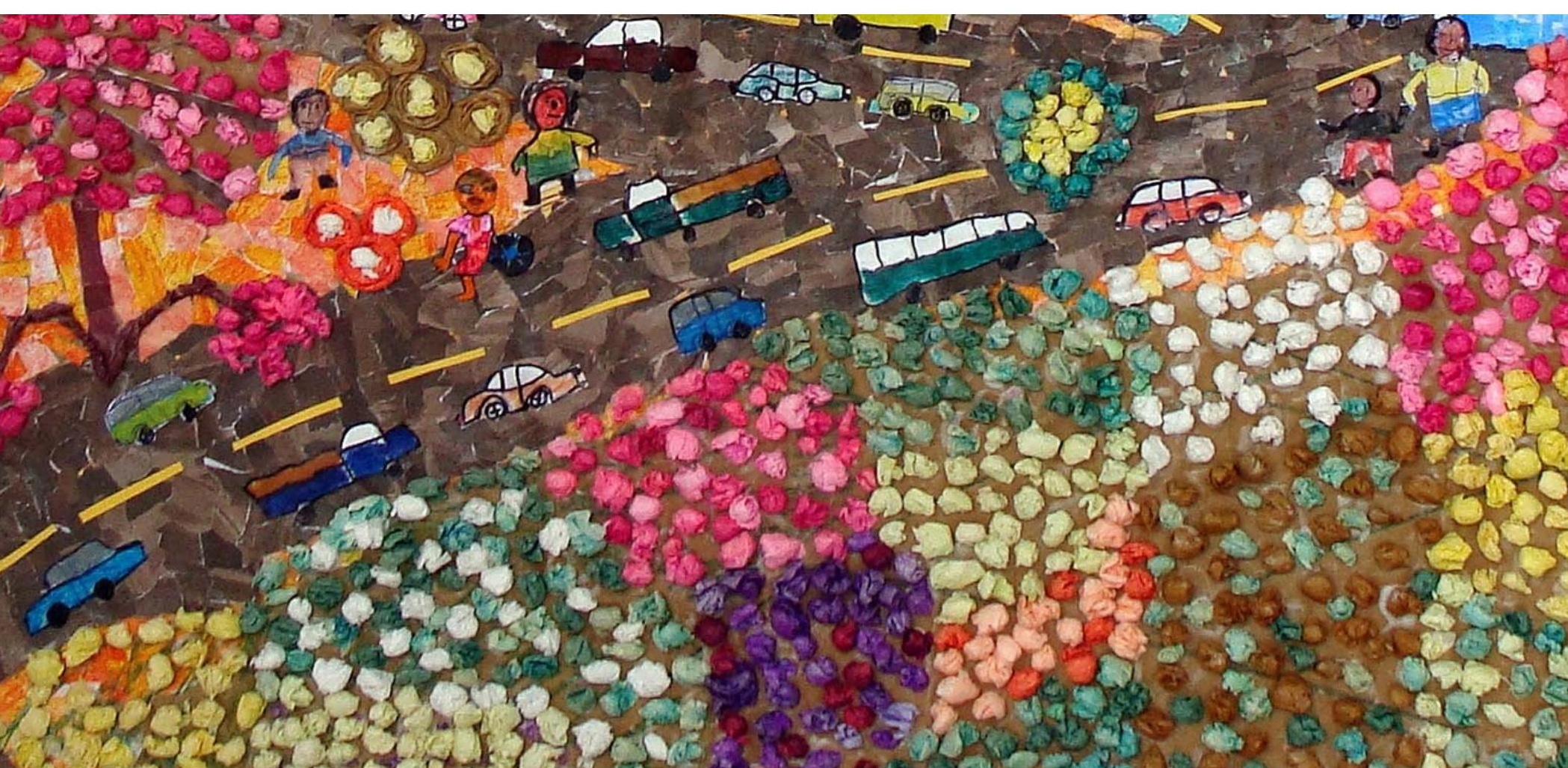

